\title{
PREPARATION AND LUMINESCENT PROPERTIES OF $\mathrm{ZnTe}^{-\mathrm{Cd}_{1-x}} \mathrm{Mn}_{x} \mathrm{Te}_{1-y} \mathrm{Se}_{y}$ HETEROJUNCTION*
}

\author{
Le Van KhoI, W. Dobrowolski, B. Witkowska, A. Mycielski, \\ R.R. GALĄZKA \\ Institute of Physics, Polish Academy of Sciences, \\ Al. Lotników 32/46, 02-668 Warszawa, Poland

\section{AND NguYen The KHoI} \\ Institute of Experimental Physics, Warsaw University \\ Hoża 69, 00-681 Warszawa, Poland
}

\begin{abstract}
$\mathrm{ZnTe}-\mathrm{Cd}_{1-x} \mathrm{Mn}_{x} \mathrm{Te}_{1-y} \mathrm{Se}_{y}$ heterojunctions were prepared by vaportransport epitaxy of $\mathrm{ZnTe}$ on In-doped $\mathrm{Cd}_{1-x} \mathrm{Mn}_{x} \mathrm{Te}_{1-y} \mathrm{Se}_{y}(x=0.05$, $y=0.03$ ) single crystalline substrate in vacuum. At temperatures lower than $120 \mathrm{~K}$ the infrared and red electroluminescence were observed from the $\mathrm{ZnTe}-\mathrm{Cd}_{1-x} \mathrm{Mn}_{x} \mathrm{Te}_{1-y} \mathrm{Se}_{y}$ diode with forward current density in the range $0.003-4.0 \mathrm{~A} / \mathrm{cm}^{2}$.

PACS numbers: $78.60 . \mathrm{Fi}$
\end{abstract}

\section{Introduction}

Diluted magnetic semiconductors (DMS) have recently generated a great deal of interest not only for basic investigations but also for device applications [1]. Heterojunction between the DMS of $\mathrm{A}_{1-x}^{\mathrm{II}} \mathrm{Mn}_{x} \mathrm{~B}^{\mathrm{VI}}$ type and $\mathrm{A}^{\mathrm{II}} \mathrm{B}^{\mathrm{VI}}$ compounds may give new possibility to fabricate electroluminescence devices. In this paper we report the fabrication method of $\mathrm{ZnTe}-\mathrm{Cd}_{1-x} \mathrm{Mn}_{x} \mathrm{Te}_{1-y} \mathrm{Se}_{y}$ heterojunction and its luminescent properties.

\section{Preparation of $\mathrm{ZnTe}-\mathrm{Cd}_{1-x} \mathrm{Mn}_{x} \mathrm{Te}_{1-y} \mathrm{Se}_{y}$ heterojunction}

$\mathrm{ZnTe}-\mathrm{Cd}_{1-x} \mathrm{Mn}_{x} \mathrm{Te}_{1-y} \mathrm{Se}_{y}$ heterojunctions were formed by vapor-transport epitaxy of $\mathrm{ZnTe}$ on In-doped $\mathrm{Cd}_{1-x} \mathrm{Mn}_{x} \mathrm{Te}_{1-y} \mathrm{Se}_{y}(x=0.05, y=0.03$, In: $5 \times 10^{18} \mathrm{~cm}^{-3}$ ) single crystalline substrates, cleaved along (110) surfaces from the as-grown crystal. The electron concentration in substrate material was from 1 to $3 \times 10^{17} \mathrm{~cm}^{-3}$ at room temperature. Single crystals of $\mathrm{ZnTe}$ prepared by Bridgman method were used as the evaporating source. The growth of the $\mathrm{ZnTe}$

*This work is in part supported by the State Committee for Scientific Research (Republic of Poland) under grant No. 204759101. 
epitaxial layer was performed in a quartz reactor pumped down to $1 \times 10^{-6} \mathrm{~mm} \mathrm{Hg}$ and placed in a horizontal two-zone temperature furnace.

The results of electron diffraction and metallographic observation showed that the quality of the layer structure depends on the source and substrate temperatures. Single crystalline $\mathrm{ZnTe}$ films can be obtained at the source and substrate temperatures $1150 \pm 5^{\circ} \mathrm{C}$ and $580 \pm 5^{\circ} \mathrm{C}$, respectively. Figure 1 shows the surfaces of non-etched $\mathrm{ZnTe}$ layers grown on $\mathrm{Cd}_{1-x} \mathrm{Mn}_{x} \mathrm{Te}_{1-y} \mathrm{Se}_{y}$ single crystalline substrate and on mica. It can be seen from Fig. 1 that the ZnTe epitaxial layer grows on $\mathrm{Cd}_{1-x} \mathrm{Mn}_{x} \mathrm{Te}_{1-y} \mathrm{Se}_{y}$ substrate in (110) direction, while on mica in (111) direction.
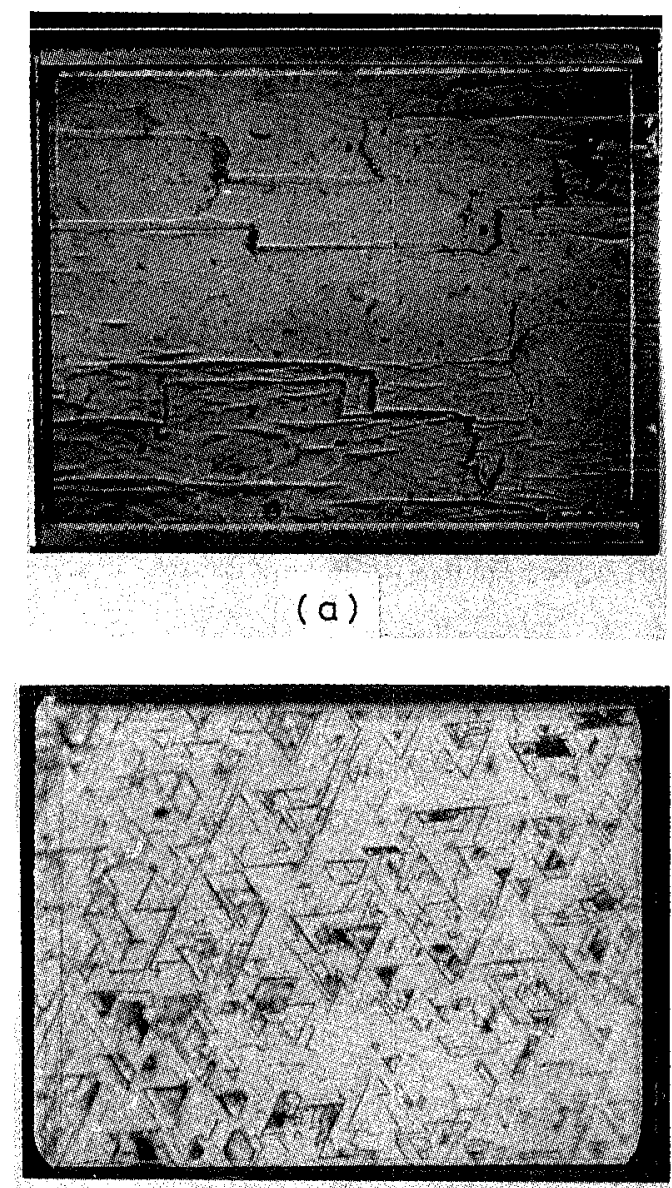

(b)

Fig. 1. Surface of $\mathrm{ZnTe}$ layers grown on $\mathrm{Cd}_{1-x} \mathrm{Mn}_{x} \mathrm{Te}_{1-y} \mathrm{Se}_{y}$ (a) and mica (b). 
$\mathrm{ZnTe}-\mathrm{Cd}_{1-x} \mathrm{Mn}_{x} \mathrm{Te}_{1-y} \mathrm{Se}_{y}$ diodes were formed by soldering In contact to $\mathrm{Cd}_{1-x} \mathrm{Mn}_{x} \mathrm{Te}_{1-y} \mathrm{Se}_{y}$ substrate and by evaporating $\mathrm{Au}$ film on the $\mathrm{ZnTe}$ layer, followed by thermal annealing at $410^{\circ} \mathrm{C}$ for $10 \mathrm{~s}$. The size of the diodes was about $1.0 \times 1.0 \times 0.5 \mathrm{~mm}^{3}$. The current-voltage characteristics of the obtained diodes were measured at temperature range $2-300 \mathrm{~K}$. They showed that in the dark, the forward current was about $10^{4}$ times higher than the reverse one at $1 \mathrm{~V}$. Almost all the diodes exhibit interesting switching effect when the applied voltage changes. The switching threshold depends on temperature and on external illumination. The reverse current varies intensively with external illumination. These effects depend on the "history" of the diode".

\section{Luminescencent properties of $\mathrm{ZnTe}-\mathrm{Cd}_{1-x} \mathrm{Mn}_{x} \mathrm{Te}_{1-y} \mathrm{Se}_{y}$} heterojunction

We measured the reflectivity and photoluminescence spectra of the CdMnTeSe substrate material and the ZnTe epitaxial layers grown on CdMnTeSe (110) substrate.

The photoluminescence (PL) spectrum of $\mathrm{Cd}_{0.95} \mathrm{Mn}_{0.05} \mathrm{Te}_{0.97} \mathrm{Se}_{0.03}$ crystal excited by $\mathrm{He}-\mathrm{Ne}$ or Ar laser at $4.2 \mathrm{~K}$ is characterized by four bands: the most intensive band with peak at $1.45 \mathrm{eV}$ and three broad bands of weaker intensities with peaks at $1.6,1.63$ and $1.65 \mathrm{eV}$. From the PL and reflectivity spectra of the crystal, we determined the band gap energy of this material equal to $1.65 \mathrm{eV}$.

Electroluminescence (EL) measurement was performed in the temperature region $2-120 \mathrm{~K}$ by passing through the diode a stabilized forward current ranging from 0.03 to $40 \mathrm{~mA}$ (about $0.003-4.0 \mathrm{~A} / \mathrm{cm}^{2}$ ). The radiation from the diode was led out for measurement in the plane parallel to the junction. The spectral distribution was analysed by a GMD 1000 double grating monochromator with a dispersion of about $3.0 \mathrm{~cm}^{-1}$ and detected by a HAMAMATSU $\mathrm{R}$ 943-02 photomultiplier in photon-counting regime.

Figure 2 shows the spectra of the electroluminescence (EL) of the $\mathrm{ZnTe}-\mathrm{Cd}_{1-x} \mathrm{Mn}_{x} \mathrm{Te}_{1-y} \mathrm{Se}_{y}$ diode and photoluminescence (PL) of the substrate materials at $4.2 \mathrm{~K}$. The EL spectrum consists of two regions: a relatively intensive and narrow peak at about $1.45 \mathrm{eV}$ (so far called the main peak) and a long "tail" in the range from $1.6 \mathrm{up}$ to $1.9 \mathrm{eV}$. It is worth noting that the intensity of the main peak depends on the density of the forward current $(J)$ and reaches its maximum at $J \sim 16 \mathrm{~A} / \mathrm{cm}^{2}$ (see insert in Fig. 3). Besides, the relative intensity of the main peak to the tail increased with the forward current (see Fig. 3), but the position of the observed bands is independent of the current.

Measurements of EL in magnetic fields up to $5 \mathrm{~T}$ showed no change in peaks position for both circular polarizations.

From the analysis of the EL spectra of the $\mathrm{ZnTe}-\mathrm{Cd}_{1-x} \mathrm{Mn}_{x} \mathrm{Te}_{1-y} \mathrm{Se}_{y}$ diode, for the moment, we interpret the emission band with peak at $1.45 \mathrm{eV}$ as caused by radiative recombination of the acceptor-donor pairs in the region of the junction situated at the $\mathrm{Cd}_{1-x} \mathrm{Mn}_{x} \mathrm{Te}_{1-y} \mathrm{Se}_{y}$ substrate side. The wide band in the region from $1.6 \mathrm{eV}$ to $1.9 \mathrm{eV}$ would be due to recombination of the injected electrons on

*The details of these studies will be published elsewhere. 


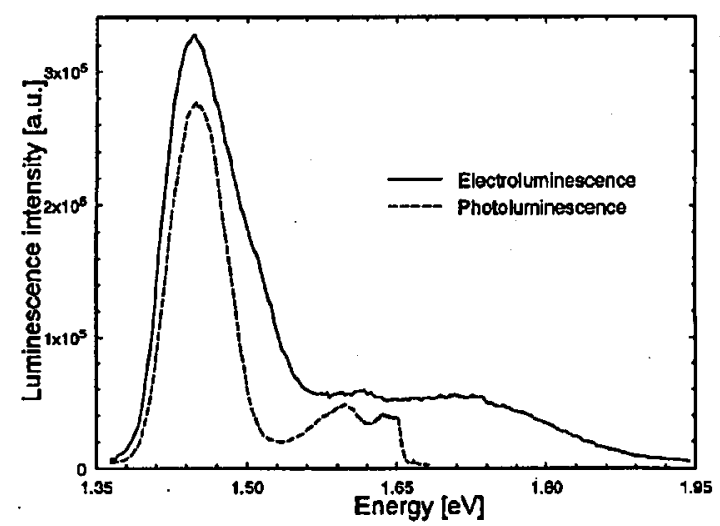

Fig. 2. Electroluminescence spectrum of $\mathrm{ZnTe}-\mathrm{Cd}_{0.95} \mathrm{Mn}_{0.05} \mathrm{Te}_{0.97} \mathrm{Se}_{0.03}$ diode (solid line) and photoluminescence spectrum of $\mathrm{Cd}_{0.95} \mathrm{Mn}_{0.05} \mathrm{Te}_{0.97} \mathrm{Se}_{0.03}$ substrate (dashed line).

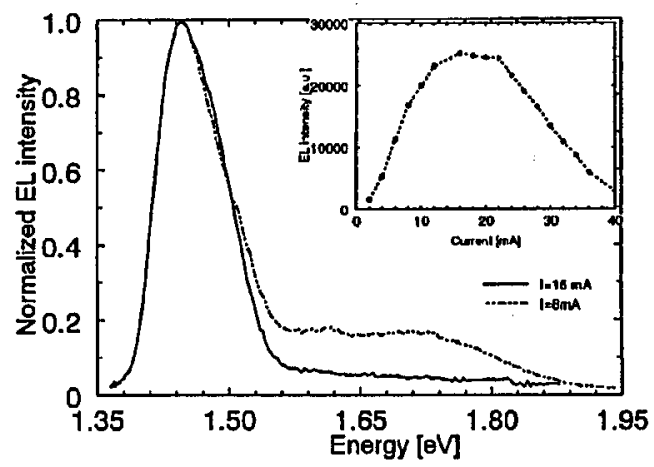

Fig. 3. Electroluminescence spectra normalized to the main peak, for two values of the current: $16 \mathrm{~mA}$ (solid line) and $8 \mathrm{~mA}$ (dashed line). In the insert: EL intensity at the main peak as a function of the current intensity.

deep levels in $\mathrm{ZnTe}$ layer side of the junction and probably, partially by excitonic recombination in the substrate side.

\section{Acknowledgments}

The authors would like to thank Prof. J.A. Gaj for enabling magneto-optical measurements on his setup.

\section{References}

[1] Diluted Magnetic Semiconductors, Eds. J.K. Furdyna, J. Kossut, Semiconductors and Semimetals, Vol. 25, Academic Press, New York 1988. 